\title{
Design of a Branch-line Microstrip Coupler Using Spirals and Step Impedance Cells for WiMAX Applications
}

\author{
Sayed M. Hosseini and Abbas Rezaei \\ Department of Electrical Engineering, Kermanshah University of Technology, Kermanshah, Iran
}

\begin{abstract}
A branch-line microstrip coupler is designed and fabricated in this paper. The proposed coupler operates at $3 \mathrm{GHz}$, which is suitable for WiMAX applications. The designed coupler has a high performance, that is, a low phase difference of $0.49^{\circ}$, low insertion loss, good coupling factor, and good isolation better than $-30 \mathrm{~dB}$. Another advantage of the designed coupler is its novel geometrical structure based on integrating the semi-circular and step impedance cells. The design process is based on introducing and analyzing an equivalent $L C$ model to improve impedance matching and reduce losses. To verify the design process, the designed coupler is fabricated, where a good agreement between the simulation result and measurement is achieved.
\end{abstract}

Index Terms-Branch line, Coupler, Insertion loss, Microstrip, Phase shift.

\section{INTRODUCTION}

Modern wireless communication systems usually require highperformance microstrip devices to meet low cost and high performance (Noori and Rezaei, 2017a; Noori and Rezaei, 2017b; Noori and Rezaei, 2017c). Accordingly, several types of branch-line couplers in Kumar and Karthikeyan, 2015; Wang, et al., 2016; Salehi and Noori, 2014; Sa'ad, et al., 2014; Shukor and Seman, 2015; Jung, 2014; Sa'ad, et al., 2013; Zong, et al., 2014; Kumar, et al., 2016; Tsai, et al., 2014; Dwari and Sanyal, 2006; Salehi, et al., 2015; and Rezaei and Noori, 2018, have been proposed to be used in modern monolithic microwave integrated circuits. For examples, they can be used in balanced mixers, balanced amplifiers, and phase shifters. A microstrip coupler is designed in Kumar and Karthikeyan, 2015, which is based on open stubs and triple open complementary split-ring resonator. Utilizing this structure led to the size reduction. Using a substrate of integrated suspended line, a novel branch-line coupler has

ARO-The Scientific Journal of Koya University

Vol. VIII, No.1 (2020), Article ID: ARO.10606, 4 pages

DOI: $10.14500 /$ aro.10606

Received 02 December 2019; Accepted 08 January 2020

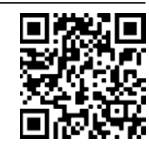

Regular research paper: Published 20 February 2020

Corresponding author's e-mail: a.rezaee@kut.ac.ir

Copyright (C) 2020 Sayed M. Hosseini and Abbas Rezaei. Rashid.

This is an open-access article distributed under the Creative

Commons Attribution License. been implemented by Wang, et al. (2016). To reduce the coupler size, Wang, et al. (2016) utilized several meander lines. The designed branch-line coupler by Salehi and Noori (2014) operates at $2.4 \mathrm{GHz}$ for wireless local area networks. This coupler has good characteristics such as compact size, high isolation, and negligible phase imbalance. A novel transparent $3 \mathrm{~dB}$ branch-line coupler has been introduced by $\mathrm{Sa}$ 'ad, et al. (2014) using a nanoparticle technology. A twosection microstrip-slot branch-line coupler for enhanced bandwidth performance has been presented in Shukor and Seman, 2015. In this structure, an overlapped $\lambda / 4$ opencircuited line has been added to each port, whereas each branch of coupler is composed of a microstrip-slot line. Meanwhile, the shunt branches have been bended for size reduction. A branch-line coupler based on an interdigital capacitor and quarter-wavelength strips are reported by Jung (2014). Using this structure, wide bandwidth and compact size have been obtained. In Sa'ad, et al., 2013, a branch-line coupler using open cross stub meander lines technique with a symmetrical structure has been introduced. In Zong, et al., 2014, several interdigital capacitors have been utilized to design a microstrip branch-line coupler. It has compact size with low insertion and return losses and high isolation. In Kumar, et al., 2016, a branch-line coupler has been reported with multiple asymmetric $\pi$-shaped, cross-shaped, and T-shaped transmission lines to reduce the overall size of coupler. In Tsai, et al., 2014, a compact branch-line hybrid coupler with suppressed harmonics has been presented. It has the advantages of the $2^{\text {nd }}$ harmonic suppression capability and good frequency selectivity. In Dwari and Sanyal, 2006, a high harmonic suppression microstrip coupler based on stopband characteristics of defected ground structure sections has been introduced. These reported couplers have some disadvantages. In Alhalabi, et al., 2018, a 3-dB branch-line coupler operating at $2.45 \mathrm{GHz}$ has been proposed which is fabricated on a double-layer substrate to have a compact size. In Hosseinkhani and Roshani, 2018, a compact branch-line coupler operating at $1.5 \mathrm{GHz}$ microstrip has been designed using microstrip meandered lines and low-pass resonators. In Letavin, 2019, the miniaturization of a microstrip branch-line coupler has been proposed by replacing the microstrip transmission line with the equivalent microstrip structures with the same phase shift. In Sha, et al., 2019, a novel compact branch- 
line microstrip coupler with wide suppression band has been presented. In Gholami and Yagoub, 2018, an innovative design of microstrip-to-waveguide transition integrated with a microstrip directional coupler has been introduced. In Tan and Yassin, 2017, a novel design of a microstrip planar coupler with enhancement of power coupling has been presented. In Chen and Yeo, 2007, a symmetrical four-port microstrip coupler has been presented for crossover application. In references (Kumar and Karthikeyan, 2015; Wang, et al., 2016; Shukor and Seman, 2015; Jung, 2014; Zong, et al., 2014; Kumar, et al., 2016; Tsai, et al., 2014; Dwari and Sanyal, 2006), the phase shifts are more than $1^{\circ}$. In Kumar and Karthikeyan, 2015; Wang, et al., 2016; Salehi and Noori, 2014; Sa'ad, et al., 2014; Sa'ad, et al., 2013; Zong, et al., 2014; Kumar, et al., 2016, the coupling factors and insertion losses are not good. The designed couplers in Shukor and Seman, 2015; Jung, 2014, have large return losses. In this paper, we propose a branch-line coupler based on analyzing a novel microstrip structure. The proposed coupler has the advantages of small phase imbalance, acceptable return loss, low insertion loss, high isolation, and good coupling factor. Our designed coupler works at $3 \mathrm{GHz}$. Hence, it is suitable to WiMAX applications. It can separate the desired WiMAX signals near $3 \mathrm{GHz}$ from an antenna. Then, it transmits the desired signals to two separated ports and delivers them. The designing process is structured as follows: First, an equivalent $L C$ circuit of a basic microstrip structure is presented. Then, the $L C$ circuit is analyzed to obtain a perfect impedance matching. Finally, a microstrip coupler is designed using the presented basic structure and optimization method.

\section{COUPLER Design}

Fig. 1(a) depicts the proposed basic microstrip structure. It consists of the steps, spiral lengths, and semi-circular cells. The presented basic structure is symmetric. An equivalent $L C$ circuit of this basic structure is presented in Fig. 1(b). In this figure, the physical lengths $l_{a}, l_{b}, l_{c^{\prime}}, l_{d}$ and $l_{e}$ are replaced by the inductors $L_{1}, L_{2}, L_{3}, L_{4}$, and $L_{5}$, respectively. The input and output ports are connected to the wider cells with the equivalent capacitors $C_{1}$. The effect of steps is significant at the frequencies higher than $10 \mathrm{GHz}$. Hence, in the $L C$ model, the effect of steps is removed so the $L C$ circuit is an approximated model.

The input impedance of the $L C$ model can be calculated as follows:

$$
Z_{i n}=\frac{2}{j \omega c_{1}}+j 2 \omega L_{1}+j \omega \frac{2 L_{2} L_{4}}{L_{2}+L_{4}}+j \omega \frac{L_{3} L_{5}}{L_{3}+L_{5}}
$$

Where, $\omega$ is an angular frequency. The transmission matrix of the proposed $L C$ circuit is defined as follows: (Noori and Rezaei, 2017a; Noori and Rezaei, 2017b):

$$
T=\left[\begin{array}{ll}
A & B \\
C & D
\end{array}\right]=\left[\begin{array}{cc}
1 & Z_{\text {in }} \\
0 & 1
\end{array}\right]
$$

To have a perfect impedance matrix, the reflection coefficient $(\Gamma)$ must be zero. Therefore, it can be written as follows:

$$
\begin{aligned}
& \Gamma=\frac{A+B-C-D}{A+B+C+D}=0 \Rightarrow Z_{\text {in }}=0 \Rightarrow \\
& \frac{2}{j \omega_{r} c_{1}}+j 2 \omega_{r} L_{1}+j \omega_{r} \frac{2 L_{2} L_{4}}{L_{2}+L_{4}}+j \omega_{r} \frac{L_{3} L_{5}}{L_{3}+L_{5}}=0 \Rightarrow \\
& 2\left(L_{3}+L_{5}\right)\left(L_{2}+L_{4}\right)-\omega_{r}^{2} c_{1}\left[2 L_{1}\left(L_{3}+L_{5}\right)\left(L_{2}+L_{4}\right)+\right. \\
& \left.L_{3} L_{5}\left(L_{2}+L_{4}\right)+2 L_{2} L_{4}\left(L_{3}+L_{5}\right)\right]=0 \Rightarrow \\
& \omega_{r}=\sqrt{\frac{2\left(L_{3}+L_{5}\right)\left(L_{2}+L_{4}\right)}{c_{1}\left[2 L_{1}\left(L_{3}+L_{5}\right)\left(L_{2}+L_{4}\right)+L_{3} L_{5}\left(L_{2}+L_{4}\right)\right.}} \\
& \left.+2 L_{2} L 4\left(L_{3}+L_{5}\right)\right]
\end{aligned}
$$

Since $\omega_{\mathrm{r}}$ is obtained by $Z_{\text {in }}=0$, it is the angular resonance frequency (Noori and Rezaei, 2017c). We can put the target angular resonance frequency instead of $\omega_{\mathrm{r}}$. There is a high degree of freedom to tune the inductors and capacitor to have a defined $\omega_{r}$. Accordingly, they can be obtained by optimization method. Meanwhile, we have a perfect impedance matching, which leads to improve losses. These inductors and capacitors must be selected so that the overall dimensions are miniaturized. Using this structure, a microstrip coupler with a symmetric geometry is designed, as shown in Fig. 2. The additional optimizations are carried out to get better performance. It consists of two basic structures integrated by the step impedance cells. The coupling factor and insertion loss are affected by the width of vertical stubs, whereas the other parameters are unchanged. Moreover, changing the physical lines (those are inside the semi-circles) leads to improve the return loss and isolation factor.

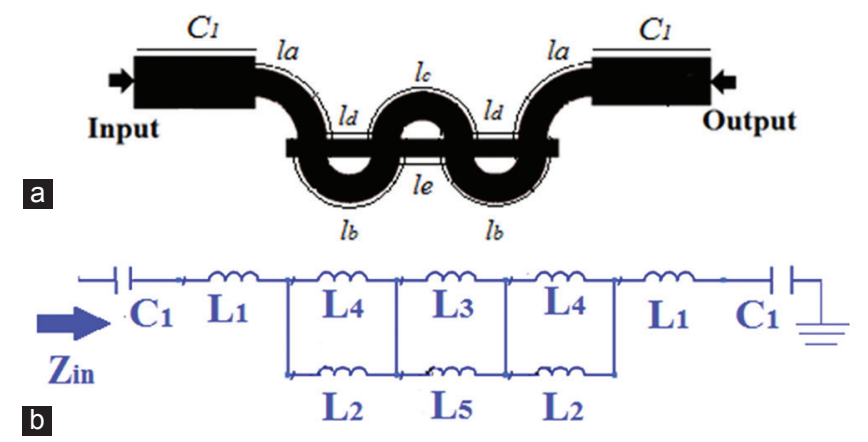

Fig. 1. The basic microstrip structure (a) layout, (b) equivalent $L C$ circuit.

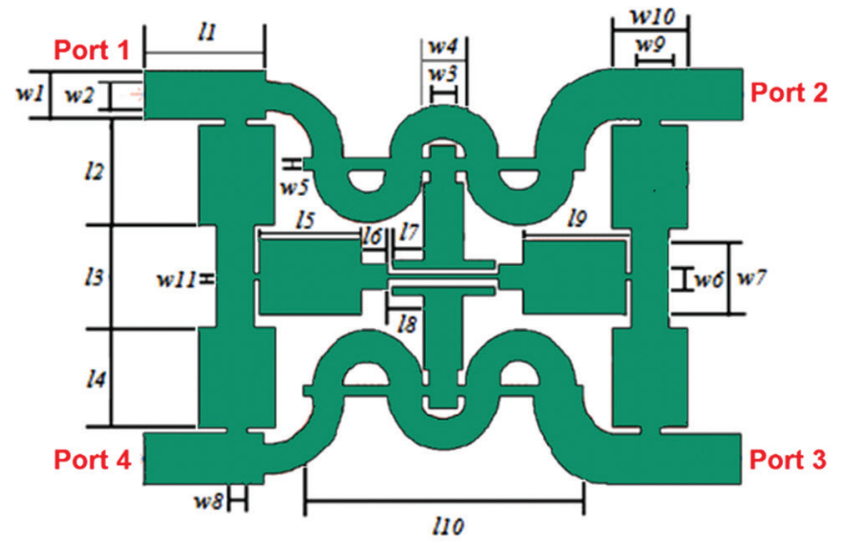

Fig. 2. Layout of the proposed coupler. 


\section{RESUlTS AND DiscUSSION}

The designed structure is simulated by electromagnetic simulator of advanced design system software. We used $\mathrm{RT}_{\text {/duroid }}{ }^{\circledR} 5880$ substrate for simulation and fabrication of the proposed coupler. RT/duroid ${ }^{\circledR} 5880$ substrate is used with the dielectric constant, dielectric thickness, and loss tangent of $2.2,0.7874 \mathrm{~mm}$, and 0.0009 , respectively. Figs. $3 \mathrm{a}$ and b
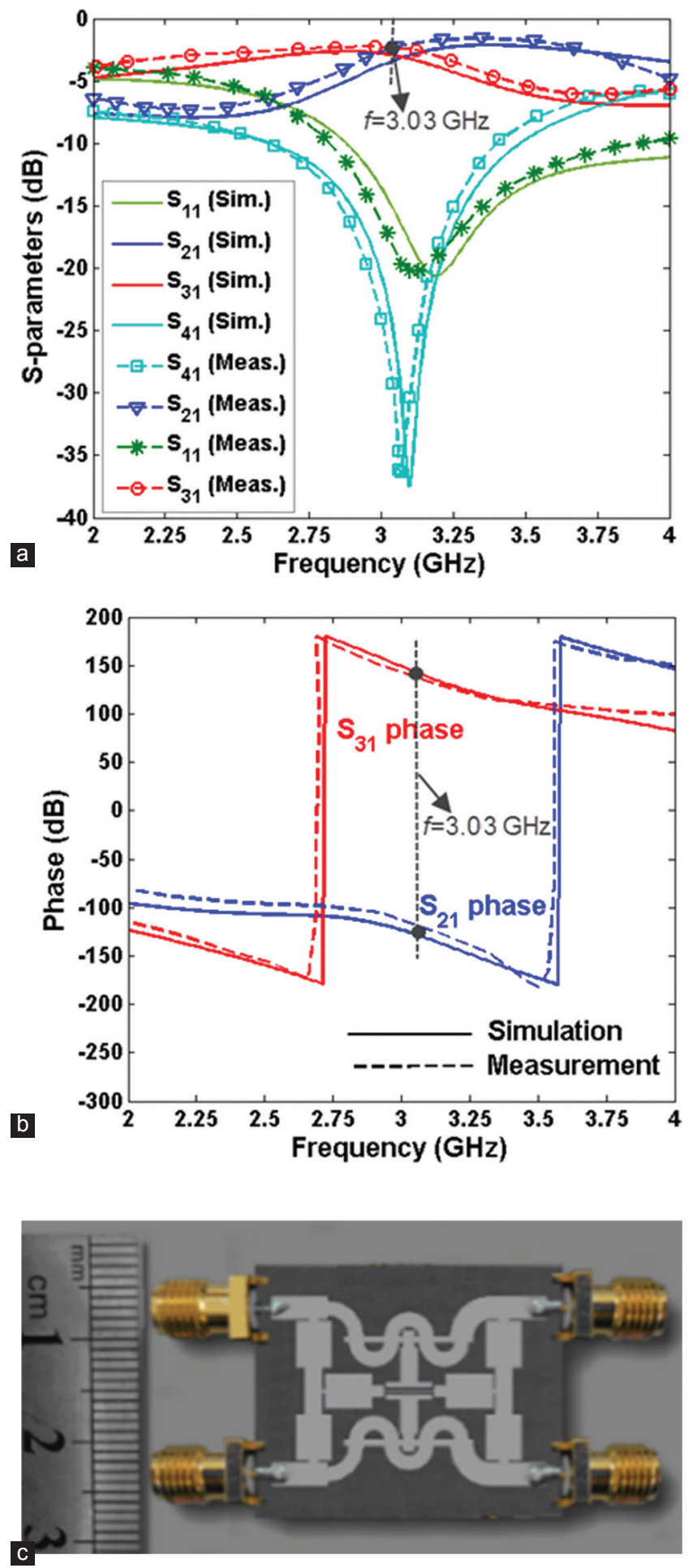

Fig. 3. (a) Simulated and measured frequency response of the proposed coupler, (b) simulated and measured phases of $S_{21}$ and $S_{31}$, (c) fabricated coupler. show the frequency response of the designed coupler. The proposed coupler works at $3 \mathrm{GHz}$. A photograph of the fabricated circuit is provided in Fig. 3c.

The occupied area of the proposed coupler is $0.22 \lambda_{\mathrm{g}} \times 0.32 \lambda_{\mathrm{g}}(23.5 \mathrm{~mm} \times 16.5 \mathrm{~mm})$ where $\lambda_{\mathrm{g}}$ is the guided wavelength calculated at the resonance frequency. At the center frequency of $3 \mathrm{GHz}$, the common port reflection coefficient $\left(\left|S_{11}\right|\right)$ and isolation $\left(\left|S_{41}\right|\right)$ are $17 \mathrm{~dB}$ and $34 \mathrm{~dB}$, respectively. Meanwhile, the transmission coefficients $\left(\left|S_{21}\right|\right.$ and $\left.\left|S_{31}\right|\right)$ are 3.07 and $3.17 \mathrm{~dB}$, respectively. The fabricated structure is measured by an Agilent network analyzer N5230A. The simulated phase difference between the output ports is $270.49^{\circ}$. In Table I, the dimensions (in $\mathrm{mm}$ ) of our branch-line coupler are presented. Table II depicts a comparison between this work and the previous reported couplers in terms of phase shift, common port return loss $\left(S_{11}\right)$, insertion loss $\left(S_{21}\right)$, coupling factor $\left(S_{31}\right)$, isolation $\left(S_{41}\right)$, and area. According to the comparison table, the proposed couplers in Kumar and Karthikeyan, 2015; Salehi and Noori, 2014; Jung, 2014; Sa'ad, et al., 2013; Zong, et al., 2014; Kumar, et al., 2016; Tsai, et al., 2014; and Dwari and Sanyal, 2006, are small, but we can see the large phase shifts and undesired isolation factors in Kumar and Karthikeyan, 2015; Jung, 2014; Sa'ad, et al., 2014; Kumar, et al., 2016; Tsai, et al., 2014; and Dwari and Sanyal, 2006. Moreover, there are the large insertion losses in the designs proposed in

TABLE I

Dimensions of the Proposed Branch-Line Coupler

\begin{tabular}{lccccc}
\hline \hline Symbol & Value & Symbol & Value & Symbol & Value \\
\hline$l_{1}$ & 4.75 & $l_{8}$ & 1.42 & $\mathrm{w}_{5}$ & 0.5 \\
$l_{2}$ & 4.2 & $l_{9}$ & 4.2 & $\mathrm{w}_{6}$ & 1 \\
$l_{3}$ & 4.1 & $l_{10}$ & 11 & $\mathrm{w}_{7}$ & 3 \\
$l_{4}$ & 4 & $\mathrm{w}_{1}$ & 2 & $\mathrm{w}_{8}$ & 0.8 \\
$l_{5}$ & 4 & $\mathrm{w}_{2}$ & 1.25 & $\mathrm{w}_{9}$ & 1.5 \\
$l_{6}$ & 1 & $\mathrm{w}_{3}$ & 1 & $\mathrm{w}_{10}$ & 3 \\
$l_{7}$ & 1.25 & $\mathrm{w}_{4}$ & 1.5 & $\mathrm{w}_{11}$ & 0.3 \\
\hline \hline
\end{tabular}

TABLE II

Comparison with the Previous Designs

\begin{tabular}{lcccccc}
\hline \hline Refs. & $S_{11}(\mathrm{~dB})$ & $S_{21}(\mathrm{~dB})$ & $S_{31}(\mathrm{~dB})$ & $S_{41}(\mathrm{~dB})$ & $\begin{array}{c}\text { Phase } \\
\text { shift }\end{array}$ & Area $\left(\lambda_{\mathrm{g}} \times \lambda_{\mathrm{g}}\right)$ \\
\hline This work & 17 & 3.05 & 3.16 & 34 & $0.49^{\circ}$ & $0.22 \times 0.32$ \\
Kumar and & 19.67 & 3.67 & 3.31 & 23.03 & $2.5^{\circ}$ & $0.41 \times 0.08$ \\
Karthikeyan, 2015 & & & & & & \\
Wang, et al., 2016 & 30 & 3.75 & 3.85 & 20 & $1^{\circ}$ & $0.33 \times 0.33$ \\
Salehi and Noori, & 21.4 & 3.3 & 3.3 & 42.9 & $0.09^{\circ}$ & $0.23 \times 0.1$ \\
2014 & & & & & & \\
Sa'ad, et al., 2014 & 20.2 & 4.3 & 3.9 & 23.5 & $0.2^{\circ}$ & $0.45 \times 0.39$ \\
Shukor and & 10 & $3 \pm 2$ & $3 \pm 1.6$ & 10 & $5^{\circ}$ & $0.93 \times 0.35$ \\
Seman, 2015 & & & & & & \\
Jung, 2014 & 10 & - & - & 30 & $2^{\circ}$ & $0.29 \times 0.20$ \\
Sa'ad, et al., 2013 & 20 & 3.51 & 3.36 & 20 & $0.5^{\circ}$ & $0.27 \times 0.25$ \\
Zong, et al., 2014 & 35 & 2.94 & 3.72 & 35 & $3^{\circ}$ & $0.1 \times 0.11$ \\
Kumar, et al., 2016 & 23.15 & 3.68 & 3.28 & 20.34 & $2.5^{\circ}$ & $0.20 \times 0.16$ \\
Tsai, et al., 2014 & 23.2 & 3.9 & - & 28.9 & $2^{\circ}$ & $0.077 \times 0.072$ \\
Dwari and Sanyal, & 22 & 3.2 & 3.1 & 17 & $2^{\circ}$ & $0.12 \times 0.12$ \\
2006 & & & & & & \\
Rezaei and Noori, & 29 & 3.3 & 2.8 & 31.3 & $0.97^{\circ}$ & $0.29 \times 0.26$ \\
2018 & & & & & & \\
\hline \hline
\end{tabular}


Kumar and Karthikeyan, 2015; Salehi and Noori, 2014; Jung, 2014; Sa'ad, et al., 2013; Zong, et al., 2014; Kumar, et al., 2016; Tsai, et al., 2014; and Dwari and Sanyal, 2006.

Meanwhile, the lowest phase shift has been obtained in Sa'ad, et al., 2014, but it has large occupied area, low isolation factor, and large insertion loss.

\section{CONCLUSION}

In this work, a $90^{\circ}$ branch-line microstrip coupler is designed, fabricated, and measured to operate at $3 \mathrm{GHz}$ for WiMAX applications. The proposed coupler is based on a symmetrical configuration, which consists of the semi-circular and step impedance cells. An $L C$ approximate model of the basic microstrip structure is proposed to obtain the conditions for a good impedance matching. Meanwhile, we improved the coupler features using an optimization method, according to the presented theory method. Novel structure, low loss, low phase shift, and relatively good isolation are the advantages of the proposed microstrip coupler.

\section{REFERENCES}

Alhalabi, H., Issa, H., Pistono, E. and Kaddour, D., 2018. Miniaturized branchline coupler based on slow-wave microstrip lines. International Journal of Microwave and Wireless Technologies, 10(10), pp.1103-1106.

Chen, Y. and Yeo, S.P., 2007. A symmetrical four-port microstrip coupler for crossover application. IEEE Transactions on Microwave Theory and Techniques, 55(11), pp.2434-2438.

Dwari, S. and Sanyal, S., 2006. Size reduction and harmonic suppression of microstrip branch-line coupler using defected ground structure. Microwave and Optical Technology Letters, 48(10), pp.1966-1969.

Gholami, M. and Yagoub, M.C.E., 2018. Integrated microstrip-to-waveguide transition with microstrip directional coupler. IEEE Microwave and Wireless Components Letters, 28(5), pp.389-391.

Hosseinkhani, F. and Roshani, S., 2018. A compact branch-line coupler design using low-pass resonators and meandered lines open stubs. Turkish Journal of Electrical Engineering and Computer Sciences, 26, pp.1164-1170.

Jung, Y., 2014. Wideband branch line coupler using symmetrical four-strip interdigitated coupler. Electronics Letters, 50(6), pp.452-454.

Kumar, K., Barik, R. and Karthikeyan, S., 2016. A novel two section branch line coupler employing different transmission line techniques. AEU-International Journal of Electronics and Communications, 70, pp.738-742.

Kumar, K. and Karthikeyan, S., 2015. Wideband three section branch line coupler using triple open complementary split ring resonator and open stubs. $A E U$ -
International Journal of Electronics and Communications, 69(10), pp.1412-1416.

Letavin, D., 2019. Miniature microstrip branch line coupler with folded artificial transmission lines. AEU-International Journal of Electronics and Communications, 99, pp.8-13.

Noori, L. and Rezaei, A., 2017a. Design of a microstrip diplexer with a novel structure for WiMAX and wireless applications. AEU-International Journal of Electronics and Communications, 77, pp.18-22.

Noori, L. and Rezaei, A., 2017b. Design of a microstrip dual-frequency diplexer using microstrip cells analysis and coupled lines components. International Journal of Microwave and Wireless Technologies, 9(1), pp.1467-1471.

Noori, L. and Rezaei, A., 2017c. Design of microstrip wide stopband quad-band bandpass filters for multi-service communication systems. AEU-International Journal of Electronics and Communications, 81, pp.136-142.

Rezaei, A. and Noori, L., 2018. Microstrip hybrid coupler with a wide stop-band using symmetric structure for wireless applications. Journal of Microwaves, Optoelectronics and Electromagnetic Applications, 17(1), pp.23-31.

Sa'ad, B., Rahim, S. and Dewan, R., 2013. Compact wide-band branch-line coupler with meander line, cross, and two-step stubs. Microwave and Optical Technology Letters, 55(8), pp.1810-1815.

Sa'ad, B., Rahim, S., Peter, T., Rani, M., Ausordin, S., Zaidel, D. and Krishnan, C., 2014. Transparent branch-line coupler using micro-metal mesh conductive film. IEEE Microwave and Wireless Components Letters, 24(12), pp.857-859.

Salehi, M., Noori, L. and Abiri, E., 2015. Novel tunable branch-line coupler for WLAN applications. Microwave and Optical Technology Letters, 57(5), pp.1081-1084.

Salehi, M. and Noori, L., 2014. Novel $2.4 \mathrm{GHz}$ branch-line coupler using microstrip cells. Microwave and Optical Technology Letters, 56(9), pp.21102113.

Sha, S., Ye, Y. and Zhang, Z., 2019. A novel microstrip branch-line coupler with wide suppression band. Progress in Electromagnetics Research Letters, 83, pp.139-143.

Shukor, N. and Seman, N., 2015. Enhanced design of two-section microstripslot branch line coupler with the overlapped $\lambda / 4$ open circuited lines at ports. Wireless Personal Communications, 88(3), pp.467-478.

Tan, B.K. and Yassin, G., 2017. Planar microstrip coupler with enhanced power coupling. Electronics Letters, 53(1), pp.34-36.

Tsai, K., Yang, H., Chen, J. and Chen, Y., 2014. A miniaturized 3 dB branchline hybrid coupler with harmonics suppression. IEEE Microwave and Wireless Components Letters, 21(10), pp.537-539.

Wang, Y., Ma, K. and Mou, S., 2016. A compact branch line coupler using substrate integrated suspended line technology. IEEE Microwave and Wireless Components Letters, 26(2), pp.95-97.

Zong, B., Wang, G., Zhang, C. and Wang, Y., 2014. Miniaturised branch-line coupler with ultra-wide high suppression stopband. Electronics Letters, 50(19), pp.1365-1367. 